\title{
OIL PRICES
}

\section{Volatile spillovers \\ Energy Econ. 80, 310-320 (2019)}

Volatility in markets is a measure of how rapidly a market moves and generally indicates investor uncertainty. How volatility in stock markets affects or 'spills over into' volatility in crude oil prices has long interested both investors and academics. Studying this spillover, Feng $\mathrm{Ma}$ and colleagues at Southwest Jiaotong, Yangtze Normal and Hohai universities have now found that volatility in oil prices makes Chinese and US stock markets much more volatile than vice versa, indicating greater pessimism about oil markets.

The researchers looked at crude oil prices in futures contracts and data from the Shanghai stock exchange index and the US stock exchange S\&P 500 index from 2007 to 2016 . They studied the overall volatility spillovers as well as directional spillovers, that is, how volatility in oil prices affected volatility in Chinese and US stock markets and how those stock markets affected volatility in oil prices. They also decomposed volatility into good volatility - which results in positive returns for investors - versus bad volatility, where the net returns are negative. In addition to an asymmetry in volatility spillovers - where oil markets affected stock markets more than the other way around - they found that bad volatility spillovers dominated over good volatility spillovers, indicating dominance of cautiousness about oil futures. They also found that the volatility spillovers strengthened during financial crises, which demonstrates the ability of financial uncertainty to permeate different markets.

Fouad Khan

Published online: 13 March 2019

https://doi.org/10.1038/s41560-019-0360-z 